\section{Severe Infantile Coarctation and Mid Aortic Stenosis in Williams Syndrome}

\author{
Lousararian Marina, Troglia Ana, Cabrera María J and Alday Luis E* \\ Divisions of Pediatric Cardiology and Cardiology, Hospital Aeronáutico and Sanatorio Allende, \\ Córdoba, Argentina
}

\section{Abstract}

We report a challenging patient with Williams syndrome and severe coarctation of the aorta. As in a few similar cases reported, several surgical and catheter interventions for recoarctation, intrastent intimal proliferation and stenosis of the left sub-clavian artery were required. Aortic patch angioplasty is planned for the future in a grower child.

\section{Introduction}

Deletion of chromosome 7q11.23 coding the elastin gene (ELN) causes Williams syndrome (WS), an infrequent congenital widespread disorder with up to $85 \%$ of cases with cardiovascular involvement $[1,2]$. The most frequent cardiac anomalies are supra-valvular aortic stenosis, pulmonary artery stenosis, and mitral valve prolapse. Other anomalies like pulmonary valve stenosis, septal defects, coarctation of the aorta (COA), and mid aortic stenosis, can also be found although much less frequently [3]. The last two lesions may present in neonates and infants with particular severity posing challenging situations due to recurrences with the present treatment options [4-6]. One of such patients is herein reported. The institution review boards approved the patient's report and there was parental consent. The operators involved in the interventional procedures were qualified experienced specialists in the subject.

\section{Case Report}

A 5 month-old male, $5 \mathrm{~kg}$ weight, with WS phenotype confirmed by FISH test, had an end-to-end anastomosis for severe COA at age one week. He was referred for irritability and poor weight gain. Femoral pulses were absent with upper limb systolic blood pressure of $190 \mathrm{mmHg}$. A multislice CT showed left aortic arch with bi-carotid trunk and recurrent coarctation measuring $1.9 \mathrm{~mm}$ in diameter while the transverse arch, the mid aorta, and the aorta at diaphragm level measured 2.8, 3.6, and $5.0 \mathrm{~mm}$ respectively (Figure 1). Associated anomalies were moderate right PAS, inguinal hernias, and horseshoe kidney.

Cardiac catheterization and aortogram for stent angioplasty were performed showing similar diameters

\section{More Information}

*Address for Correspondence: Alday Luis E, Divisions of Pediatric Cardiology and Cardiology, Sanatoria Allende, Córdoba, Argentina, Tel: 54 351 4214666; Fax: 54351 4694219;

Email: lealday@arnet.com.ar

Submitted: 12 July 2019

Approved: 29 July 2019

Published: 30 July 2019

How to cite this article: Lousararian M, Troglia A, Cabrera M, Alday Luis E. Severe Infantile Coarctation and Mid Aortic Stenosis in Williams Syndrome. J Cardiol Cardiovasc Med. 2019; 4: 080-082.

doi: 10.29328/journal.jccm.1001044

Copyright: () 2019 Lousararian M, et al. This is an open access article distributed under the Creative Commons Attribution License, which permits unrestricted use, distribution, and reproduction in any medium, provided the original work is properly cited

Keywords: Recurrent coarctation; Angioplasty

Abbreviations: ELN: Elastin Gene; BA: Balloon Angioplasty; COA: Coarctation Of the Aorta; WS: Williams Syndrome

Check for updates

to those described in the CT (Figure 2A and B). Pressure measurements are shown in Table 1. The peak systolic gradient across the coarctation decreased markedly after stenting with a $29 \mathrm{~mm}$ long Genesis XD stent delivered over a 5F 5 by $30 \mathrm{~mm}$ balloon catheter. Control aortogram showed a well expanded stent with a uniform $5 \mathrm{~mm}$ diameter similar to that of the descending aorta.

The patient was discharged on aspirin and enalapril and throughout the follow-up persisted growth failure with epi-

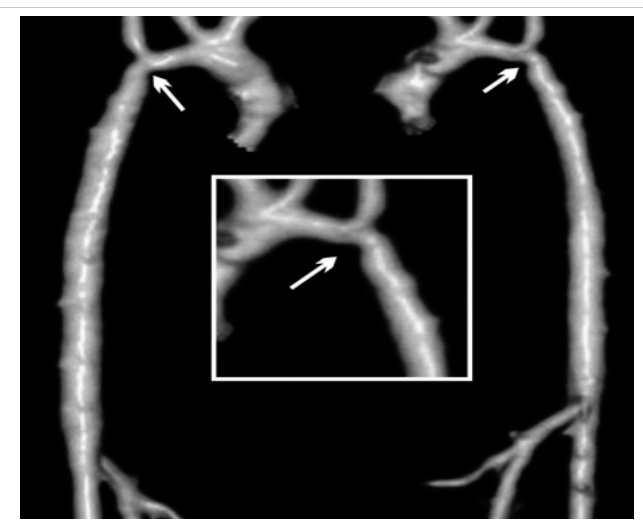

Figure 1: Multi-slice CT at the age of 5 months. There is recurrent coarctation of the aorta (arrow) with hypoplasia of the transverse arch extending to the thoracic aorta (see text for diameters at different levels). 
sodes of bronchial hyper reactivity and reduced femoral pulses with brachial arterial pressure of 130/80 mmHg. Doppler echocardiography a year later confirmed new recoarctation. Balloon angioplasty (BA) of the stent was performed 2 months later after several postponements due to bronchial hyper reactivity. In this procedure (Figure $\mathbf{3 A}$ and $\mathbf{B}$, Table $\mathbf{1}$ ), the aortogram showed a long in-stent severe irregular stenosis secondary to intimal growth beginning after the origin of the left sub-clavian artery which had ostial involvement, not present in the initial angioplasty, extending up to the distal end of the stent. The stent was dilated successfully with a 3 F $8 \times 20$ $\mathrm{mm}$ balloon catheter. However, the aortic lumen did not reach the wall of the stent because of intimal and medial aortic layer thickening. There was no aortic wall damage and there was again a marked gradient decrease through the coarctation.

Enalapril was continued and dual anti aggregation was started with clopidogrel and aspirin. On follow-up the femoral pulses were weaker than the right brachial. Blood pressures could not be measured for persistent excessive irritability. At the time of multislice CT under general anesthesia, noninvasive blood pressure showed normal values for the right arm and moderate increase in the coarctation gradient (Table 1). CT imaging findings were no different to those following BA. The descending aorta distal to the stent remained narrowed reassuming a normal caliper at the diaphragm level. Two more BAs for recurrent coarctation were performed at age $3 y$ $5 \mathrm{~m}$ and $5 \mathrm{~m}$ later. The former with right axillary artery access for recoarctation distal to the left subclavian artery which had severe ostial stenosis and subclavian steal (Figure 4A). The intrastent intimal proliferation was much less prominent than in the previous procedure and the coarctation diameter almost doubled (Figure 4B). The other intervention from the right femoral artery addressed the sub-clavian stenosis with disappearance of subclavian steal. The patient continues with antihypertensive and dual antiaggregation therapy. An extended patch angioplasty is expected in the future (Figure 4 A,B).

\section{Discussion}

Localized COA, with or without mid aortic stenosis with extended narrowing of the thoracic aorta, is an uncommon

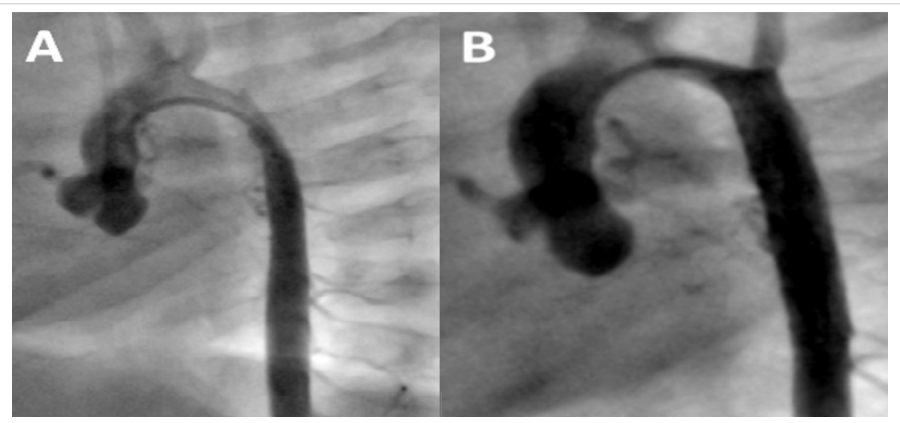

Figure 2: Stenting Procedure for Recurrent Coarctation at age 5 months. A: Pre stenting aortogram shows the coarctation and mid aortic stenosis; B: Post stent angioplasty depicts uniform diameter of the descending aorta from the coarctation site up to the diaphragm level.
Table 1: Systemic Pressures and Gradient across Coarctation at the Time of Interventions and Imaging FU. All Procedures under General Anesthesia.

\begin{tabular}{|c|c|c|c|}
\hline $\begin{array}{c}\text { Age (month)-Weight } \\
(\mathbf{k g})\end{array}$ & Procedure & $\begin{array}{c}\text { Site-Pressures } \\
\mathbf{m m H g} \\
(\mathbf{p r e - p o s t )}\end{array}$ & $\begin{array}{c}\text { Gradient } \\
\mathbf{m m H g}\end{array}$ \\
\hline $51 / 2-5.2$ & Stenting & $\begin{array}{c}\text { AA: } 112 / 53-90 / 30 \\
\text { DA: } 60 / 44-75 / 39\end{array}$ & $\begin{array}{c}\text { Pre-52 } \\
\text { Post-15 }\end{array}$ \\
\hline $21-8.4$ & Balloon Angioplasty & $\begin{array}{c}\text { AA: } 137 / 51-106 / 44 \\
\text { DA: } 75 / 49-85 / 57\end{array}$ & $\begin{array}{c}\text { Pre-62 } \\
\text { Post-21 }\end{array}$ \\
\hline $35-8.4$ & MSCT & $\begin{array}{r}\text { RA } \\
\text { Leg }\end{array}$ & 34 \\
\hline $41-12.2$ & Balloon Angioplasty & $\begin{array}{c}\text { TA: } 85 / 45-105 / 60 \\
\text { DA: } 64 / 53-83 / 53\end{array}$ & $\begin{array}{c}\text { Pre-21 } \\
\text { Post-22 }\end{array}$ \\
\hline $46-12.2$ & Balloon Angioplasty & $\begin{array}{c}\text { AA: } 116 / 63-136 / 70 \\
\text { DA: } 83 / 55-105 / 69\end{array}$ & $\begin{array}{c}\text { Pre-33 } \\
\text { Post-31 }\end{array}$ \\
\hline
\end{tabular}

AA: Ascending Aorta; DA: Descending Aorta; RA: Right Arm; LSA: Left Sub-clavian Artery; TA: Transverse Arch; MSTC: Multi-slice Computed Tomography
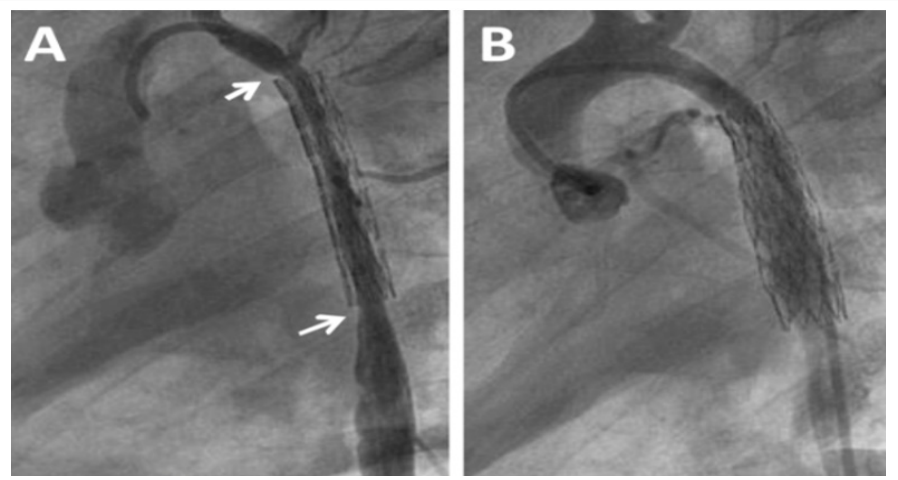

Figure 3: Balloon Angioplasty for Recurrent Coarctation at age 21 months. A: Diffuse narrowing of the mid aorta with severe intimal proliferation (between arrows); B: Recovery of the aortic lumen post balloon angioplasty.
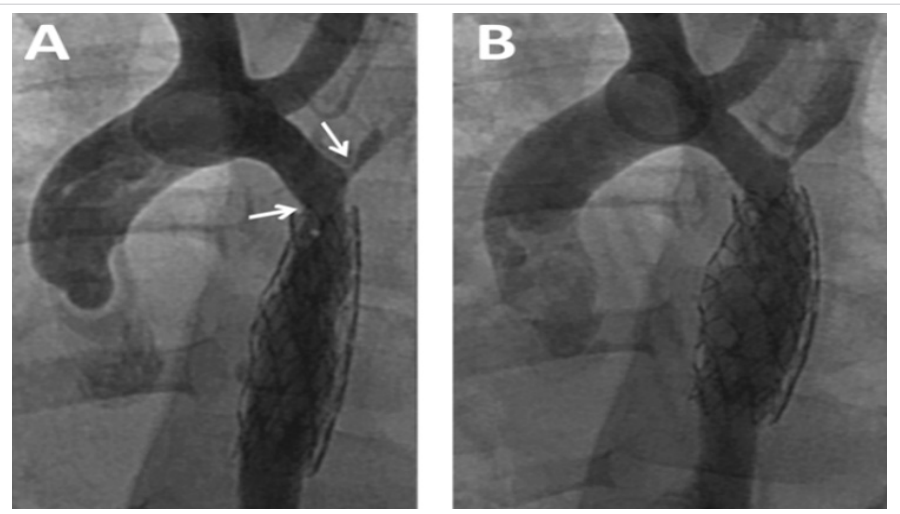

Figure 4: Balloon Angioplasty for Recurrent Coarctation at age 41 months. A: Recurrent coarctation proximal to the stent (left arrow). Severe stenosis at the origin of the left sub-clavian artery (right arrow). Intrastent proliferation much less evident than in previous procedure; B: Successful dilatation of the coarctation with right axillary approach. The sub-clavian stenosis was addressed with femoral artery approach in a following procedure.

anomaly in infants with WS [3]. However, this is the most frequent cause of early surgical or catheter intervention with subsequent high re-intervention rate secondary to neointimal proliferation at the coarctation level extending to the thoracic aorta related to the ELN deletion [4-6]. Aside its role in vascular elasticity, elastin modulates proliferation and migration of smooth muscular cells and its deficiency facilitates this process leading to sub-endothelial arterial luminal narrowing [2]. Though middle aortic syndrome is somewhat frequent in WS, it rarely occurs in infants [7]. Still, 
Table 2: Main Features and Procedures in Reported Patients with WS and Infantile COA.

\begin{tabular}{|c|c|c|c|c|c|}
\hline $\begin{array}{c}\text { Patient number and Age at } \\
\text { referral }\end{array}$ & Sex and weight (kg) & $\begin{array}{c}\text { Genetic diagnosis at } \\
\text { presentation }\end{array}$ & Cardiovascular Anomalies & Number and type of procedures & Author \\
\hline Neonate & Male - 2.7 & Yes & Long segment $\mathrm{COA}$ & $\begin{array}{l}\text { 2: Surgery sub-clavianflap + } \\
\text { patch }\end{array}$ & Marks, 2004 [5] \\
\hline 3 Weeks & Male - NA & Yes-Biopsy & Long segment COA, PAS & 1: Allograft patch & Arrington, 2005 [9] \\
\hline Neonate & Female - NA & No & Long segment COA, BAV, VSD & 3: Surgery, BA, Surgery & Hall, 2009 [10] \\
\hline 10 Days & Male - 3.1 & No & Discrete COA & 3: Surgery, BA, Surgery (conduit) & Kammache, 2010 [6] \\
\hline 2 Days & Male - 2.5 & No & Discrete COA, VSD, ASD & 3: Surgery, BA, Surgery (patch) & Kammache, 2010 [6] \\
\hline $2 \frac{1}{2}$ Months & Male -4.0 & Yes & Discrete COA, BAV & 2: Surgery, Surgery (patch) & Kammache, 2010 [6] \\
\hline 1 Month & Female - 2.4 & No & Discrete COA & 3: Surgery, BA, Surgery (patch) & Mannarino, 2015 [10] \\
\hline Neonate & Male - 2.7 & Yes & Long segment COA, PAS & 5: Surgery, Stent, BA 3 times & Lousararian, 2018 (present) \\
\hline
\end{tabular}

the aortic obstruction may progress very rapidly requiring early interventions [7-10]. In a group of 8 WS patients with neonatal symptomatic coarctation reported in the literature, including ours, a total of 22 surgical or catheter interventions were required in a short time period (Table 2). Interestingly, WS was diagnosed at presentation in only half of them. Five had surgery as neonates and 3 shortly after. A second intervention was required in 7 patients between the ages of 3 to 6 months. There were 4 catheter procedures and 3 patch aortoplasties. Between the ages of 3 months and 11 years, 7 more procedures were required ( $4 \mathrm{BAs}, 2$ patch angioplasties and a bypass from ascending to descending aorta in the oldest patient).

No mortality occurred in the interventions, but the long term outlook is guarded. In our patient, following the neonatal surgery, 4 more percutaneous interventions have been performed for recurrences, the first with stent implantation. After the next recurrence showing severe intimal proliferation in the mid aorta, dual antiaggregation was started. The third recurrence did not involve the mid aorta but showed severe recoarctation in the original site and stenosis in the proximal left sub-clavian artery with sub-clavian steal syndrome. The latter requiring another BA. However, antiplatelet therapy might have somewhat prevented intimal growth.

Collins' review on WS, mentions pharmacological interventions that might be appropriate to address elastin deficiency including the possibility of tissue engineering of blood vessels in surgical interventions [2]. Nevertheless, there is still no experience with these therapies in humans. Hopefully, with nowadays medical advances, they could be available in the future. Otherwise, patch angioplasties could be performed in older children.

\section{Conclusion}

Infantile COA and WS, an uncommon and aggressive disorder, often associated with mid aortic involvement shows multiple recurrences with the present care strategies used in patients without WS. Dual antiplatelet treatment seems to be effective in reducing in stent intimal proliferation. Patch angioplasty could be useful in older children. Since this is a very unusual association more cases are needed to draw more definitive conclusions with regard to the best treatment option, including the use of dual antiplatelet aggregation and the development of novel pharmacological interventions.

\section{References}

1. Bruno E, Rossi N, Thüer O, Córdoba R, Alday LE. Cardiovascular findings, and clinical course, in patients with Williams's syndrome. Cardiol Young. 2003; 13: 532-536. PubMed: https://www.ncbi.nlm.nih. gov/pubmed/14982294

2. Collins RT. Cardiovascular disease in Williams's syndrome. Circulation. 2013; 127: 2125-2134. PubMed: https://www.ncbi.nlm.nih.gov/ pubmed/23716381

3. Collins RT, Kaplan P, Rome JJ. Stenosis of the thoracic aorta in Williams's syndrome. Pediatr Cardiol. 2010; 31: 829-833. PubMed: https://www.ncbi.nlm.nih.gov/pubmed/20411252

4. Eronen M, Peippo M, Hiippala A, Raatikka M, Arvio M, et al. Cardiovascular manifestations in 75 patients with Williams's syndrome. J Med Genet. 2002; 39: 554-558. PubMed: https://www.ncbi.nlm.nih.gov/pmc/ articles/PMC1735199/

5. Marks JL, Mitchell MB, Campbell DN, Toews WH. Composite aortoplasty for recurrent coarctation after neonatal repair in Williams's syndrome. Ann Thorac Surg. 2004; 77: 319-321. PubMed: https:// www.ncbi.nlm.nih.gov/pubmed/14726089

6. Kammache I, Accar P, Kreitmann B, Fraisse A. Williams-Beuren syndrome: A unusual cause of neonatal and infantile coarctation. $J$ Thorac Cardiovasc Surg. 2010; 140: e80-81. PubMed: https://www. ncbi.nlm.nih.gov/pubmed/20832827

7. Radford DJ, Pohlner PG. The middle aortic syndrome: an important feature of Williams'syndrome. Cardiol Young. 2000; 10: 597-602. PubMed: https://www.ncbi.nlm.nih.gov/pubmed/11117392

8. Arrington C, Tristani-Firouzi M, Puchalski M. Rapid progression of longsegment coarctation in a patient with Williams' syndrome. Cardiol Young. 2005; 15: 312-314. PubMed: https://www.ncbi.nlm.nih.gov/ pubmed/15865838

9. Hall EK, Glatz J, Kaplan P, Kaplan BS, Hellinger J, et al. A case report of rapid progressive coarctation and severe middle aortic syndrome in an infant with Williams's syndrome. Congenit Heart Dis. 2009; 4: 373-377. PubMed: https://www.ncbi.nlm.nih.gov/pubmed/19740193

10. Mannarino S, Keizman E, Pasotti M, Codazzi AC, De Sando E, et al. A rare case of discrete aortic coarctation in Williams-Beuren syndrome. Diagnostic and therapeutic considerations. Pediatr Med Chir. 2015; 37: 120. PubMed: https://www.ncbi.nlm.nih.gov/pubmed/26429123 